\title{
COLLATERAL CONFLICTS AND EPISTEMIC NORMS
}

\author{
J. Adam Carter \\ University of Glasgow
}

Abstract. This paper focuses on a specific kind of (epistemic) normative conflict, collateral normative conflict - viz., where cognition's working badly at the global level of general dispositions to believe is the price to be paid for its working well locally. I argue that such normative conflicts are much rarer than Williamson (2021) and Lasonen-Aarnio (2010) take them to be, even though, and contra proponents of revisionary defeat (e.g., Brown 2018), knowers can, as Williamson and Lasonen-Aarnio rightly maintain, at least sometimes disregard misleading evidence from reliable sources. My rationale for the rarity of collateral epistemic conflicts draws from recent insights by Sosa (2021) on the appropriateness of aiming, in certain domains of inquiry, not just at knowledge, but at knowledge firsthand. A consequence of the rationale offered, however, is that an entirely different kind of normative conflict - what I call cross-modal normative conflict turns out to be much more common than appreciated.

\section{INTRODUCTION}

A dilemma is a situation where all options are bad. An epistemic dilemma, if such a thing exists, will presumably be a situation where all epistemic options - viz., belief, disbelief, and withholding - are bad.

An epistemic option is 'bad' only if it violates an epistemic norm. So, an epistemic dilemma (again, if there is such a thing) will at least be a situation where all epistemic options involve the breach of an epistemic norm.

Some epistemic norms govern belief. Here is an example: believe that $p$ only if you know that $p .{ }^{1}$ Assume, for the sake of argument, that that norm is correct. If so, then - as one popular line of thought goes ${ }^{2}-$ we should also accept derivative norms, norms that are then applicable when we assess the agents whom the original norm governs. ${ }^{3}$ One such deriva-

\footnotetext{
${ }^{1}$ For some representative defences of this view, see, e.g., Williamson (2002), Gibbons (2013), Littlejohn (2013), Swindlehurst (2020). For an overview, see Benton (2014).

${ }^{2}$ See Williamson (2016).

${ }^{3}$ See Williamson $(2021,12)$. For a more detailed articulation of the relationship between 'primary' norms, that take the form: 'do X' and derivative norms that govern individuals to
} 
tive norm governs our general belief-forming dispositions: this derivative norm says to manifest knowledge-conducive cognitive dispositions.

As Williamson (2021) points out, if you breach the belief norm, this results in a kind of 'local failure'; this is because what constitutes the breach is a defect in the belief, not a defect in the wider cognitive system. If you breach the latter derivative norm, this results in a kind of 'global failure'; this is because what constitutes the breach is a defect in the wider cognitive system, not a defect in the belief.

A properly working cognitive system that produces knowledge breaches neither a local norm on belief nor a global norm on general dispositions to believe. ${ }^{4}$ A careless guess that issues in a false belief breaches both.

What about 'mixed' cases? These are more complicated. As Williamson says:

As theorists, we may feel ambivalent about the mixed cases, of local failure without global failure, or of global failure without local failure $(2021,7)$.

For example, we may feel ambivalent about whether to prioritise the norm compliance that features in such cases over the norm breach, or vice versa. Such ambivalence is part and parcel with the kind of normative conflict that is characteristic of these global/local mixed cases.

However, importantly, it is a mistake to infer (i) that a situation features a genuine epistemic dilemma ${ }^{5}$; from (ii) the fact that a situation features normative conflict. As Mona Simion (Forthcoming) points out, a view on which normative conflict arises can potentially give priority weighting to one norm over another in cases of conflict such that, in cases of normative conflict, it might be false that all options are equally bad even if all options involve the violation of an epistemic norm.

I am going to remain agnostic in this paper on the matter of whether there are epistemic dilemmas in the strong sense that would not be implied by mere normative conflict. ${ }^{6}$ However, I will attempt to say something new about normative conflict itself, which epistemic dilemmas - to the extent that they exist - would entail asymmetrically. In particular, I

\footnotetext{
whom the primary norm applies, see Williamson (2016).

${ }^{4}$ For a substantive recent defence of this kind of picture, see Williamson (2017, sec. 4). ${ }^{5}$ See Hughes (2019).

${ }^{6}$ See, e.g., Hughes (2019), Littlejohn (Forthcoming), Leonard (2020), Worsnip (2016), Lasonen-Aarnio (2010), and Ross (2010).
} 
will highlight two epistemologically interesting patterns of normative conflict - what I call oblative normative conflicts and collateral normative conflicts. The latter will be the central focus, for the reason that - as will be shown - it is contentious whether such cases actually feature any normative conflict at all. On the diagnosis of these cases by Williamson (2021) and Lasonen-Aarnio (2010), there is (i) global/local normative conflict; and (ii) the subject in the case knows. On the traditional revisionary defeat diagnosis, there is (i) no global/local conflict, and (ii) the subject in the case lacks knowledge. I argue both are wrong. A better diagnosis is that such cases will - paradigmatically at least - involve no global/local normative conflict (despite appearances to the contrary), and that the agent in the case knows. This diagnosis of such cases is implied in forthcoming work by Ernest Sosa (2021). However, as I'll argue, this kind of diagnosis reveals how apparent collateral normative conflicts often enough present a thinker with a very different kind of normative conflict, one between to a first approximation - norms that govern first-hand inquiry, and ones that do not.

\section{OBLATIVE AND COLLATERAL NORMATIVE CONFLICTS}

Quality mismatches between global and local cognition give rise to what appear to be normative conflicts (Williamson 2021, 8-10). ${ }^{7}$ Consider, for example, the Preface Paradox: the author warns the reader in the preface that the book will inevitably contain errors in its thousands of claims, each well-researched by the author. This warning itself is made on excellent supporting grounds about the probability of errors in a lengthy book. But the author believes every proposition stated in the book (including the warning in the preface), so at least one of the propositions the author believes will be false and so not an item of knowledge. And yet, believing all of these propositions, including those in the preface - rather than withholding on any of them - seems to be exactly what manifesting good (i.e., knowledge-conducive) general dispositions requires.

What what we find in the Preface Paradox is a 'mixed quality' case where cognition is working globally well but locally badly. ${ }^{8}$ One interesting aspect of the Preface Paradox is that cognition's working well at the global level of general dispositions is not just accidentally related to cognition's working badly at the local level, on the occasion where it makes a mistake. The connection is tighter: as Williamson (2021) puts it, in cases like the

\footnotetext{
${ }^{7}$ Mixed cases do not exhaust epistemic dilemmas. See Williamson (2021, sec. 5) for discussion of local-local epistemic dilemmas.

${ }^{8}$ For the original presentation of this case, see Makinson (1965).
} 
Preface Paradox, cognition's working globally well 'actually makes it work badly somewhere at the local level' $(2021,10)$ - e.g., either the author's belief that the preface contains an error, or her belief that $p$, where $p$ is some claim elsewhere in the book, held on good evidence, but which is false. ${ }^{9}$

For reference, call this kind of mixed case, represented by the Preface Paradox, an oblative normative conflict, one where a local 'sacrifice' is the unavoidable cost of manifesting good knowledge-conducive global dispositions.

Oblative normative conflict: A conflict in epistemic norms is an oblative normative conflict iff cognition's working well at the global level of general dispositions to believe makes it work badly somewhere at the local level of individual beliefs.

The converse of an oblative normative conflict is a mixed case where, rather than good global quality requiring a sacrifice of local quality, good local quality instead depends on there being bad global quality. Call this converse kind of case a collateral normative conflict:

Collateral normative conflict: A conflict in epistemic norms is a collateral normative conflict iff cognition's working badly at the global level of general dispositions to believe is the price to be paid for its working well locally. ${ }^{10}$

Oblative normative conflicts, such as the Preface Paradox, never result in knowledge. This is so even though they involve the manifestation of good, knowledge-conducive dispositions. ${ }^{11}$

But what about collateral normative conflicts? Here things are contentious. As we'll see in the next section, some collateral normative

\footnotetext{
${ }^{9}$ This, at least, is Williamson's assessment of the Preface Paradox. It would of course not be a suitable reference point for distinguishing good global and bad local cognition for one who already parts ways with Williamson's approach to thinking about the case, which is contentious. For some other representative viewpoints on the epistemology of the Preface Paradox, see, e.g., Pollock (1986), Ryan (1991), and Douven (2003).

${ }^{10}$ Given that our aims in cognising are essentially local - viz., I am not reasoning for the sake of reasoning, but in order to settle a question or gain knowledge - there is really no 'sacrifice' here. You 'get the goods,' unlike the case of obliative normative conflicts, where you don't get the goods because you are, as it were, reasoning in ways by which you would usually get them.

${ }^{11}$ The idea that oblative normative conflicts never result in knowledge might look contentious, but it is actually just trivial. If a subject does attain knowledge in a given case, then the case wouldn't be a case of local failure but local success.
} 
conflicts (hereafter: collateral conflicts) involve local success - compliance with at least with a knowledge norm on belief - through withholding. These are rare; they occur only when a default sceptic - already an unlikely character - is lucky on a particular occasion to withhold. ${ }^{12}$ But other collateral epistemic dilemmas involve local success qua affirming, where that local success is predicated on the manifesting of a bad general disposition. Prima facie, such cases will be more common. Arguably, some such cases involve the acquisition of knowledge, despite apparent global failure. This, at least, is the line that Williamson (2021) and Lasonen-Aarnio (2010) take. Let's now look at collateral normative conflict cases more closely and see why the latter sort are especially contentious.

\section{COLLATERAL EPISTEMIC DILEMMAS: EXAMPLE CASES}

General dispositions to believe that make up a cognitive system can fail by being the sort of dispositions that churn out too many false beliefs. But such global failure would also be implied by a system's over-propensity to forbear. ${ }^{13}$ Extreme gullibility and extreme scepticism are both global failures; in both cases, a thinker is failing to manifest good, knowledgeconducive general belief-forming dispositions.

One kind of collateral conflict occurs when the global failure is a failure that consists in too often forbearing - and yet - it is only by that globally problematic forbearance that one attains a local success.

Here is an example:

LUCKY BIV: Consider a brain in a vat - call it Betty - frozen by sceptical doubts, and so frozen in what happens to be a

\footnotetext{
${ }^{12}$ As Nick Hughes has pointed out to me, while the default sceptic is a rare character, taking a default sceptical attitude to certain specific domains of inquiry is less so. Take, for example, the conspiracy theorist who takes, problematically, a default sceptical attitude towards anything that is agreed upon by scientists, because this conspiracy theorist believes the scientists are working together as part of a wider conspiracy. Now, add to the case that on some claim, $\mathrm{X}$, there is scientific consensus and $\mathrm{X}$ is false. (Perhaps: that jade is a natural kind.) Here our conspiracy theorist, in withholding about whether $\mathrm{X}$ is true, generates a collateral normative conflict structurally akin to Betty, even though the conspiracy theorist is not an external world sceptic. Nonetheless, occasions like the above will not be very common.

${ }^{13}$ I am using 'forbear' in line with Sosa (e.g., 2021, Ch. 3) as a genus of which withholding belief is a species. While this is a natural way to think about the relationship between the two from within a framework of performance-theoretic evaluation (which I embrace), the langauge isn't essential; the reader is free to treat the two as synonymous for the purposes here.
} 
genuine sceptical scenario. Much like a non-envatted radical Pyrrhonian might do, Betty asks herself 'What if I'm really a brain in a vat ${ }^{\prime 14}$, and in response she forbears from belief: she fails to form the belief that she is not a brain in a vat. Globally, at the level of general dispositions to believe, Betty is functioning badly; but it is because Betty functions badly that local cognition works well by avoiding a false belief (by, in this case, avoiding any belief at all).

In LUCKY BIV, Betty seems to comply with belief norms that a false belief would breach - by forbearing when affirming would have led to a false belief. At the same time, Betty breaches a norm that applies to the manifestation of general dispositions: she manifests a bad global disposition whereby she is frozen in a kind of sceptical paralysis. ${ }^{15}$

Compare LUCKY BIV now with a different collateral conflict - one where cognition's working badly at the global level of general dispositions to believe is the price to be paid for its working well locally, but where working badly globally does not involve forbearing, and neither does working well locally.

MATHEMATICIAN: A competent mathematician [Matty] has just proved a surprising new theorem. She shows her proof to several distinguished senior colleagues, who all tell her that it involves a subtle fallacy. She cannot quite follow their explanations of her mistake. In fact, the only mistake is in their objections, obscured by sophisticated bluster; her proof is perfectly valid. She puts her colleagues' criticisms out of her mind, goes ahead and believes that her proof is valid, simply on the basis of her clear understanding of how it works (Williamson 2021, 1, 10). ${ }^{16}$

Here is an interesting difference between LUCKYBIV and MATHEMATICIAN. Betty withholds judgement. And, qua withholder, she is not a candidate knower; her success is just one of avoiding ignorance. But what

\footnotetext{
${ }^{14}$ This is a modification of a case presented by Williamson $(2021,10)$.

${ }^{15}$ As Williamson (2021) points out in discussing this kind of case: 'In its past history, the tendency may often have led it into a dead end, where it failed to acquire urgently needed knowledge' $(2021,10)$. Thus, a thinker with a general tendency to all-out sceptical paralysis will not be a well-functioning cognitive disposition even if that system happens to be placed in a BIV scenario where it's withholding luckily prevents error.

${ }^{16}$ This description of MATHEMATICIAN is provided by Williamson (2021) on both pp. 1 and 10. The discussion on p. 10 adds to the case that the mathematician does come to believe the target proposition, after putting the colleagues' results out of her mind.
} 
about Matty? Might she know despite manifesting a failure of a general disposition to believe?

Of course, some will be impressed by the apparent rebutting defeater Matty acquires on the basis of her colleagues' testimony. This suggests a negative answer. However, a positive answer that explains away the apparent rebutting defeater has been defended by, along with Williamson (2021), Lasonen-Aarnio (2010) and Sosa (2021).

Let's now consider whether the apparent merits of any of these positive cases hold water, and if so, how this might require us to re-think the initial assumption that the case features a global failure to begin with, and $a$ fortiori, any global/local normative conflict.

\section{THREE DIAGNOSES}

The situation that features in the MATHEMATICIAN case is really a collateral normative conflict (as LUCKY BIV is) only if the following profile is accurate: (i) bad global cognition; (ii) good local cognition; (iii) normative conflict.

This 'bad global/good local therefore conflict' reading of MATHEMATICIAN is one that Maria Lasonen-Aarnio has championed in various places (e.g., 2010; 2014) in discussing structurally similar cases. ${ }^{17}$ Lasonen-Aarnio offers the first explanation in the literature for why the protagonist in a case like MATHEMATICIAN should be understood as having not just any old local success paired with global failure but knowledge paired with global failure. ${ }^{18}$ Lasonen-Aarnio's view, applied to the case, is that Matty is being unreasonable not taking into account her colleagues' testimony, even though it is misleading. However, as she maintains, being unreasonable is compatible with knowing. Lasonen-Aarnio (2010) writes:

[...] though reasonableness is connected with knowledge in an important way, it is not necessary for knowledge. Reasonableness is at least largely a matter of managing one's beliefs through the adoption of policies that are generally knowledge conducive, thereby manifesting dispositions to

\footnotetext{
${ }^{17}$ This kind of result will also arguably be implied by Srinivasan and Hawthorne (2013).

${ }^{18}$ Lasonen-Aarnio's assessment of 'unreasonable knowledge' cases (i.e., where knowledge can be paired with bad global cognition) actually extends more broadly than cases like MATHEMATICIAN - she includes cases of perceptual knowledge as well. For the present purposes, I am focusing only on cases with a structure like MATHEMATICIAN, where the kind of local cognition involves reasoning. The reason for this focus will be apparent in $§ 5$.
} 
know and avoid false belief across a wide range of normal cases. Subjects who stubbornly stick to their beliefs in the face of new evidence manifest dispositions that are bad given the goal of knowledge or even of true belief. But we need evaluative notions that can be satisfied without possessing a general disposition to satisfy those notions. There is no reason to think that knowledge is special in this respect: sometimes being stubborn pays off $(2010,2)$.

Proponents of revisionary defeat, (e.g., Brown 2018) will, by contrast, presumably see MATHEMATICIAN as having an entirely different profile altogether: (i) bad global cognition; (ii) bad local cognition; (iii) no normative conflict. And, indeed, we find explicit arguments for this kind of a diagnosis of MATHEMATICIAN from proponents of the 'Defeat Solution' to Kripke's Dogmatism Puzzle. ${ }^{19}$ The debate surrounding that puzzle attempts to explain in what sense knowing that $p$ isn't a license to dogmatism, given that when one knows that $p$, one can presumably infer via closure that any would-be counterevidence is misleading. ${ }^{20}$

I am not here going to weigh in on that particular puzzle. Instead, I want to explore the viability of a third kind of diagnosis of MATHEMATICIAN, which rejects both that Matty's knowledge is defeated (contra the defeat diagnosis) and, contra Williamson and Lasonen-Aarnio (hereafter: WLA), that there must be at least one kind (i.e., global or local) of epistemic norm violation. The closest extant example of this third kind of view appears in recent work by Ernest Sosa (2021Ch. 1), who describes MATHEMATICIAN-style cases as featuring (i) good global cognition; (ii) good local cognition; (iii) no normative conflict.

Thus, we have the following three distinct readings of MATHEMATICIAN.

\begin{tabular}{llll}
\hline & global & local & normative conflict \\
\hline Defeat diagnosis & bad & bad & no \\
Williamson/Lasonen-Aarnio (WLA) diagnosis & bad & good & yes \\
Sosa diagnosis & good & good & no \\
\hline
\end{tabular}

\footnotetext{
${ }^{19}$ See, e.g., Kripke (2011).

${ }^{20}$ See Kripke (2011) for the original formulation of this puzzle. For recent discussion, see Beddor (2019), Brown (2018), and Lasonen-Aarnio (2014).
} 
A point of mutual recognition between the defeat diagnosis and the and WLA diagnoses (despite their points of contention) is this: if a view rules Matty knows that her proof is valid, then (given bad global cognition) there would be global-local normative conflict.

But the Sosa diagnosis rejects this shared assumption. And that is because on the Sosa diagnosis, where Matty can count as knowing the proof is valid, there is not (despite initial appearances) any kind of global failure. Matty is not violating any epistemic norms, global or local.

Unlike the WLA diagnosis that says Matty can know even though Matty violates a global norm when Matty disregards the colleagues' testimony, Sosa's diagnosis maintains that Matty can know the proof is valid and that Matty positively should disregard the colleagues' testimony. And that's why there is not really any normative conflict here, despite initial appearances.

If Sosa is right about this, then this will generate a curious result about collateral normative conflicts - again, cases where cognition's working badly at the global level of general dispositions to believe is the price to be paid for its working well locally. The result that appears to be implied by Sosa's diagnosis of MATHEMATICIAN-style cases is that collateral normative conflicts occur at most when cognition's working badly at the global level of general dispositions to believe is the price to be paid for its working well locally by withholding (as in LUCKY BIV) - cases that will already themselves be very rare. This would mean not only that there are fewer collateral epistemic conflicts (there is no implication for oblative epistemic conflicts) than Williamson and Lasonen-Aarnio would have it, but it would also mean that proponents of revisionary defeat are - despite wrongly predicting that Matty lacks knowledge - right (contra Williamson and Lasonen-Aarnio) that bad global cognition can't issue in knowledge. Given these interesting results that are implied by Sosa's diagnosis, let's consider now the rationale for it.

\section{COLLATERAL DILEMMAS AND FIRSTHAND KNOWLEDGE}

Consider, specifically, the judgement Matty makes when she determines the proof to be valid. She is at least affirming in the endeavour to get it right about whether the proof is valid. But that is something Matty has in common with those mathematicians who affirm that Goldbach's conjecture is true, even though they lack a proof for it. ${ }^{21}$ It is even something

\footnotetext{
${ }^{21}$ Goldbach's conjecture states that every even integer greater than two is the sum of two primes. Though it remains unproven, it is widely believed to be true. Famously, Euler, in
} 
Matty has in common with a non-mathematician who, while on a gameshow, simply affirms one way or another by guessing. ${ }^{22}$

Here is an answer that looks initially plausible: Matty, in judging the validity of the proof, aims not merely to get it right, but to get it right knowledgeably. In this respect, Matty is unlike a basketball player chucking from half-court - with the aim of making it no matter the risk of error - and more like the player who assesses risk and takes a well-selected shot, aiming not just to get it right, but to get it right aptly, viz., through competence. ${ }^{23}$ This is Sosa's view. ${ }^{24}$ However, it's not the full story.

Sosa thinks there is something special going on in cases like MATHEMATICIAN, something that bears importantly on how it is that we, by judging, aim at knowledge in at least some domains of inquiry - those driven by intellectual curiosity and not merely by practical ends.

In such domains, which according to Sosa include much of humanitstic inquiry - including philosophy, logic and abstract mathematics - we aim in judging not just to get it right any old way, or even to get it right merely knowledgeably, but to get it right knowledgeably in - to a first approximation - a firsthand way. ${ }^{25}$

In this respect, curiosity-driven humanistic judgements - e.g., whether Kant's transcendental deduction is correct, whether the continuum hypothesis is correct, whether Quine disproved the analytic/synthetic distinction, etc. - are much more like the judgements we make when attempting to fill in a crossword puzzle - where sheer deference undermines one's purposes - than they are like purely practical inquiries, where knowledge acquired any way will do. Here is how Sosa elaborates on this analogy:

responding to a letter from Goldbach in 1742 said, upon first seeing the statement of the conjecture that he believed it 'even though he could not prove it' (Wang 2002, 4:1).

${ }^{22}$ For discussion of guessing, understood as affirmation in the endeavour to merely get it right (any way) - see Sosa (2015, 74-75) and (2021, 25-33, 64-65, 96-90). Cf., Carter (2016).

${ }^{23}$ For discussion, see Sosa (2010); cf., Carter (2020).

${ }^{24}$ For Sosa's initial statement of this view - which gives judgement a central place in his epistemology, see Sosa (2015Ch. 3). The view of judgement as constitutively aimed at knowledge has been developed further - within a telic virtue epistemology, in Sosa (2021). For the most recent presentation, see Sosa (2020).

${ }^{25}$ This line of argument is defended in detail in Sosa $(2021 \mathrm{Ch} .1)$. There are some aspects of the argument, including what is for Sosa the role of intuitive insight, and the role of understanding, that are important to his project, but which we can leave aside for present purposes. For a very different picture of the role of first-person insight in perceptual epistemology specifically, see Pritchard (2016). 
CROSSWORD ANALOGY: Consider two aficionados addicted to the NY Times crossword puzzle, one tries to solve the puzzle with no external aids, and often succeeds. Another always waits for the answer to be published the next day, then dutifully fills it in, and gets the solution exactly right. Why does that seem so foolish? Because the whole point of a crossword puzzle is to give you the amusement that goes with a challenge that can be met but not too easily, one that calls on your own resources and engages your attention pleasurably. Both agents want equally to get it right, yet one of them foolishly neglects the proper objective. Truth is a part of the objective, but only a part. Attaining the truth by just copying the right answer is not in the right spirit. Rather, your aim must be not just success but firsthand success. In that specific respect humanist judgements are like crossword solutions. Indeed, given our broad understanding of humanist questions, crossword puzzles constitute a light humanistic domain, where it is preferable and generally preferred to reach one's answers firsthand, not just through deference. We saw earlier how humanist value judgements properly engage one's own autonomous competence. Proper deliberation uses testimony only as a conduit to reasons which can then be accessed firsthand, adopted as one's own, and deployed through firsthand reasoning. Testimony can play that role of conduit perfectly well, since the recipient need give no weight to the word of the testifier as such $(2021,15-16)$.

If Sosa is right that in at least curiosity-driven domains of inquiry, we aim in judging at knowledge unaided by sheer deference, then, as he puts it, disagreement should not be as troubling, at least in these domains of inquiry, as it is often taken to be. ${ }^{26}$ Compare: when an archer allows their coach to guide their hands through the shot, they aim to hit the target through this aid but the desire for firsthand performance is suppressed. But this is not the case when the archer performs as a competitor. As Sosa puts it:

There I dispense with external aids. I cannot defer to a coach's direct guidance as I draw my bow and prepare to shoot. And this is so even if I still very much want to hit the

\footnotetext{
${ }^{26}$ For some views on which disagreement in philosophy and the humanities suggest that we should accept at least some kind of agnosticism or scepticism in these areas, see Ballantyne (2014), Carter (2018), and Feldman (2006). Cf., Goldberg (2013).
} 
target and know perfectly well that I could do so much more reliably with the coach's help! $(2021,15)$.

On the assumption that Matty - like humanistic inquirers, driven by curiosity - aims at judging knowledgeably firsthand - she thereby, with this goal, aims at attaining a kind of thing she wouldn't even in principle secure simply by deferring to her colleagues' sayso (any more than the archer, in competition, can attain their goal by shooting with the help of a coach or another benevolent competitor).

Sosa's view - if correct - licenses a bracketing of others' say-so, at least when one aims intentionally at judging knowledgeably firsthand - in the sense that (as in other domains where firsthand performance success is valued) 'external aids that would boost competence must be shunned' $(2021,15)$.

It should now be clear why Sosa's view looks like it promises a way to 'resolve' what - if we assume like Williamson and Lasonen-Aarnio do, that Matty has knowledge - would otherwise be an inevitable conflict between global and local epistemic norms. Just consider that Williamson and Lasonen-Aarnio both take Matty (and those in Matty's position) to know while nonetheless manifesting a bad general belief forming disposition. According to Williamson, what's bad is Matty's 'tendency to ignore criticism from well-qualified sources.' According to Lasonen-Aarnio, what's bad is that Matty (and those in her situation) is, 'being unreasonable' and by manifesting a 'defective strategy for acquiring knowledge' (2010, 16). Sosa's line - while accepting that Matty knows (contra the revisionary defeat diagnosis) - denies that she is manifesting any bad disposition whatsover. Contra Williamson, she should ignore such criticism; contra Lasonen-Aarnio, she is manifesting exactly the kind of strategy one should manifest in the service of first-hand knowledge, even if this would not be a good strategy for acquiring knowledge just any way.

\section{A FURTHER TWIST}

Let's summarise the key claims so far:

- Epistemic dilemmas and normative conflicts: Epistemic dilemmas, if they exist, asymmetrically entail normative conflicts.

- Oblative and collateral normative conflicts: Two interesting patterns of normative conflict are oblative normative conflicts and collateral normative conflicts.

- Two kinds of collateral normative conflicts: Collateral normative con- 
flicts differ with respect to whether the local success that depends on bad general cognition is a success in withholding or a success in knowing.

- Collateral normative conflicts and knowledge: The latter kind of case represented by MATHEMATICIAN - is especially contentious. The key dispute, between proponents of the revisionary defeat diagnosis and the WLA diagnosis, concerns the matter of whether the case features local success (knowledge) despite the manifesting of a bad global disposition.

- Breaking past the impasse: If Sosa is right, both sides of this debate are wrong, because MATHEMATICIAN features local success - knowledge - without the manifesting of any bad global disposition.

- Ramification of Sosa's diagnosis: Moreover, if Sosa's diagnosis is right, then this means that collateral normative conflicts are extremely rare. They are limited to those (already rare) cases where a default sceptical thinker generates a local success in withholding.

Does Sosa's diagnosis of MATHEMATICIAN hold water? In this section, I first show that his view withstands some anticipated objections; next, I'll propose a new twist: to the extent that Sosa is right, then (i) collateral normative conflicts are indeed rare - and rarer than the WLA view would have it; but - and here's the twist - (ii) another kind of normative conflict turns out to then be much more common. This other kind of normative conflict pits against each other norms that govern modes of inquiry, and by extension, beliefs and global dispositions under these (respective) modes.

\section{VI.a. Some objections deflected}

Objection: If Sosa's diagnosis of MATHEMATICIAN is correct, then Matty is - rather than a knower who manifests a bad global disposition (i.e., to ignore the colleagues' testimony) - actually manifesting a good global disposition by ignoring the colleagues' testimony. But this is a problematic result even if we grant Sosa that in the kind of inquiry Matty undertakes here, Matty aims at first-hand knowledge. One way to see why this is so is to revisit Sosa's archer analogy. Suppose an archer aims at firsthand success, and in this way, aims to hit the target not through having her hands guided by the instructor, and even if she appreciates that this would increase the chance of success. Even assuming all of this, surely the archer would be manifesting a bad disposition were the archer to - while in the heat of the hunt - simply ignore all information from her fellow hunters that bears on whether she will hit the target. For example, information 
about whether all the targets have already been eliminated in that area, whether there are any nearby realistic decoys, whether a news update predicts high winds, etc. But if this is granted, it is less clear that Matty, even if aiming at first-hand inquiry, should - as Sosa puts it - bracket the (albeit, misleading) testimony of her colleagues.

Reply: Yes, that would be a bad result, but on closer inspection, it can be avoided. Here it is helpful to distinguish between: (i) knowledge on trust, alternatively, through sheer deference; (ii) knowledge that depends on the conduit to reasons provided by testimony. The former is of course incompatible with knowing first-hand. The latter, though, is not. As Sosa himself points out, a pupil might depend on guidance from a geometry teacher in the course of coming to gain first-hand insight into a proof, e.g., of the Pythagorean theorem. Here the pupil is being made aware of reasoning that, as Sosa puts it, she can 'then make her own,' such that the success of her judgement is a first-hand-success, not deferential success, held just on another's sayso. ${ }^{27}$ What goes for the pupil goes for the archer, for whom we can distinguish accepting guidance in the aid of a first-hand success, from, e.g., deferring to the hands of the expert when making the attempt at that success.

Objection: But wait, if the archer and the pupil described can accept guidance in the course of first-hand success - in the epistemic case, this will be first-hand knowledge that depends on the conduit to reasons provided by testimony - why is Matty doing something right by retaining her belief in the face of her colleagues' testimony?

Reply: Even a thinker who aims at first-hand knowledge might be led to reconsider on the basis of another's testimony. But the line being advanced here distinguishes between revising and reconsidering. ${ }^{28}$ The claim, specifically, is that Matty - in aiming at knowledge first-hand may not only permissibly not revise simply on another's say-so, but she should not revise simply on another's say-so. ${ }^{29}$ She should not do this

\footnotetext{
${ }^{27}$ Another example Sosa gives makes reference to the guidance one receives by Descartes' in reading the Meditations. As Sosa puts it, 'These are a record of the author's meditations, but they also serve, and are surely meant to serve, as a script for the reader's own performance. A main aim of the work is the enlightenment of the reader, not through deference to the author but through guidance to firsthand insight and understanding' $(2021,14)$.

${ }^{28}$ (Sosa 2021, 14).

${ }^{29}$ At least on Sosa's line of thought, reconsidering is compatible with not revising. Take, for example, two students, both of whom have established the proof of the Pythagorean theorem on their own, in a first-hand way. The teacher, uncharacteristically, pranks the students by telling them that they have gotten something wrong. The first student, recognising the teacher as a reliable source of the kind of mathematical reasons that the student
} 
any more than the pupil should accept the Pythagorean theorem's proof on sheer deference to the teacher, or the competition archer should then succumb to external aids simply from hearing information that would affect her performance first-hand.

Objection: Alright, though even if all of the above is granted, there remains a problem, which is this: Matty, at the end of the day, is being irrational in not revising (at all) in light of her colleagues' testimony, testimony we can assume ex ante that she takes to come from sources as reliable as she. If this is granted, it is explained easily by, e.g., Williamson and LasonenAarnio's assessment that Matty (despite knowing) manifests a bad global disposition. But it's hard to square with the idea that Matty is, per Sosa, manifesting a good global disposition. Good global dispositions - in short - surely exclude irrational asymmetry of epistemic treatment.

Reply: This objection can be defused for a subtle but important reason. While asymmetric epistemic treatment that features in MATHEMATICIAN would be irrational if arbitrary, it is not arbitrary here. It is principled, given the assumption that Matty's judgement is understood as aimed at knowledge-first-hand, rather than knowledge any way. To bring this point into focus, consider that the same asymmetric treatment would be principled if the (misleading) contrary testimony was not merely from her colleagues, epistemic peers, but from - say - Terence Tao, Leonard Euler or from a superintelligence whom Matty regards as infallible. Discounting, or bracketing, the say-so of these perceived epistemic superiors is equally apposite to aiming at knowledge through first-hand competence. Note, of course, that in this more extreme case no less than in the original case, it is not at all that Matty would be thinking, irrationally, that she is more likely to be right on the matter than her colleagues, Tao, Euler, or the infallible superintelligence. That thought, regardless of her aim in inquiring, would be irrational, and $a$ fortiori, would not plausibly issue from a good (knowledge-conducive)

might then adopt on her own, reconsiders her own reasoning-broadly analogous to how a conscientious architect might look over their plans a final time before submitting. The architect is not thereby in doubt of their own plans by reconsidering them. The final "check over' is not accompanied with agnosticism about whether the plans (checked over carefully before) are right. The same goes with the first student, as she rechecks her proof. The second student, suppose, is led by the teacher's misleading testimony to reconsider also, but also to revise. She is by contrast akin to an architect who cannot check her design, at her superior's suggestion, while still affirming it as a sound design. Sosa's suggestion that reconsidering is compatible with not revising is tantamount to the idea that it is possible to be in the position of the first student, when reconsidering, and not always in the position of the second. 
global disposition. Though, crucially, she's committed to no such thing in simply not revising.

\section{VI.b. Normative conflict across modes of inquiry}

If in judging whether something $(p)$ is so - at least in certain areas in, e.g., the humanities, philosophy and mathematics - we aim not only to affirm whether $p$ knowledgeably, but to do so knowledgeably through first-hand competence, then it looks as though collateral epistemic conflicts will be comparatively rarer than Williamson and Lasonen-Aarnio would have it. And this is because a significant proper subset of these would-be cases will not involve local/global normative conflict of the sort anticipated after all. They will involve local success and global success, which is the reading of MATHEMATICIAN we've been considering, and which we've seen holds up well under scrutiny.

But even if all this is right, another very different kind of normative conflict - for reference, cross-modal normative conflict - stands waiting in the wings. This will be the focus of this section.

Let's take as a starting point that not all inquiries are like Matty's inquiry in mathematics and like humanistic inquiries more generally. Often enough, our judgements are attempts we make, by affirming, just to know any way. ${ }^{30}$ Knowledge is the norm of the latter kind of judgement, first-hand knowledge the norm of the former. What this means, then, is that the matter of what norm (knowledge or first-hand knowledge) applies to a given judgement itself depends on whether 'first-hand' conditions apply.

Let ' $F$ ' represent these conditions, $K_{F}$ first-hand knowledge, and $J_{F}$ a judgement aimed at $K_{F}$. The 'twin norms' governing judgements of both types are then:

$$
\begin{aligned}
& \left(\mathrm{NJ}_{\mathrm{F}}\right): \text { If } F \text {, you should }\left(J_{F}(p) \text { if and only if } K_{F}(p)\right) . \\
& (\mathrm{NJ}): \text { If } \neg F \text {, you should }(J(p) \text { if and only if } K(p)) .
\end{aligned}
$$

\footnotetext{
${ }^{30}$ For example, in considering whether a particular antique is valuable to sell - suppose you care nothing about antiques and just want to maximise profit - you, in judging whether to sell it by taking an expert's word - affirm in the endeavour to do so knowledgeably, with no concern to appreciate why the antique should be sold through a first-hand competence to appraise the item, understand the market, etc. To be clear, you are in judging not aiming to, through affirming whether $p$, get it right any way - e.g., a guess, appropriate to getting it right any way, would be inappropriate here - but to know anyway, first-hand or otherwise. If your judgement issues in something short of knowledge, it then falls short, but it doesn't fall short if that knowledge is based on sheer deference.
} 
For both of these norms, $\left(\mathrm{NJ}_{\mathrm{F}}\right)$ and $(\mathrm{NJ})$, there will then be corresponding derivative norms, norms that are applicable when we assess the agents whom the original norm governs.

$\left(\mathrm{D}-\mathrm{NJ}_{\mathrm{F}}\right)$ : If $F$, you should be disposed to $\left(J_{F}(p)\right.$ if and only if $\left.K_{F}(p)\right)$.

(D-NJ): If $\neg \mathrm{F}$, you should be disposed to $(J(p)$ if and only if $K(p))$.

Implied by the above picture is that, if $F$, then the norm governing one's global dispositions to believe is $\left(\mathrm{D}-\mathrm{NJ}_{\mathrm{F}}\right)$ and not (D-NJ). Matty is in $F$ conditions ex hypothesi; though she violates (D-NJ), (D-NJ) is not applicable to her. $\left(\mathrm{D}-\mathrm{NJ}_{\mathrm{F}}\right)$ is. But she doesn't violate it.

Now, here's the twist. Whether a thinker is in $F$ conditions, when deliberating about whether $p$, very plausibly depends on her own orientation to that question, which will itself be a matter of her intentions (and perhaps other mental states). For example, it might very well be that it is on account of Matty's intentionally aiming at first-hand knowledge that she is in $F$-conditions. Plausibly such intentional aiming suffices to place her in these conditions.

A ham-fisted pragmatist, who affirms whether $p$ when she does always in the endeavour to affirm knowledgeably any way - viz., where sheer deference will always do - will never be in $F$ conditions, and so will be governed in judging when she does by $(\mathrm{NJ})$ and $(\mathrm{D}-\mathrm{NJ})$, never by $\left(\mathrm{NJ}_{\mathrm{F}}\right)$ nor $\left(\mathrm{D}-\mathrm{NJ}_{\mathrm{F}}\right)$. By contrast, the hero of Emerson's Self-Reliance ${ }^{31}$ might by default be in F-conditions, and so will be governed in judging when she does by $\left(\mathrm{NJ}_{\mathrm{F}}\right)$ and $\left(\mathrm{D}-\mathrm{NJ}_{\mathrm{F}}\right)$, never by $(\mathrm{NJ})$ nor $(\mathrm{D}-\mathrm{NJ})$.

Part of what it is, plausibly, to be a good inquirer is to know when to be more like the pragmatist and when to be more like the hero of SelfReliance. ${ }^{32}$ I take this to be obvious. But, once it is granted, it is clear that the very kinds of intentions that place us in $F$-conditions are themselves norm governed. For example, for some intention or mental state, $\phi_{F}$ that triggers $F$-conditions, for some conditions, $C$, the following norm (and derivative norm) plausibly apply:

\footnotetext{
${ }^{31}$ See Emerson (1841). Equally, this kind of paradigmatically first-hand inquirer is praised by Kant (1996) in his essay 'What is Enlightenment,' in which he proposes that, when approaching any question for consideration, 'Have the courage to use your own reason.'

${ }^{32}$ Sosa (2021Ch. 2) suggests as much in his telic virtue epistemology, in which he discusses intellectual ethics - where the norms govern not constitutive attempts we make at knowing, but which inquiries we take up and to what extent we are prepared to close those inquiries.
} 
$\left(\phi_{\mathrm{F}}\right)$ : You should $\left(\phi_{F}\right.$ if and only if $\left.C\right)$.

(D- $\left.\phi_{\mathrm{F}}\right)$ : You should be disposed to $\left(\phi_{F}\right.$ if and only if $C$ ).

We're now in a position to define a cross-modal normative conflict. Suppose (i) $C$ obtains, (ii) you don't form the intention or mental state $\phi_{F}$; thus, $F$-conditions are not triggered; and then (iii) you come to know whether $p$ on sheer deference. Here you violate $\left(\phi_{\mathrm{F}}\right)$ as well as $\left(\mathrm{D}-\phi_{\mathrm{F}}\right)$, but you comply with (NJ) and (D-NJ). Thus, we have normative conflict. The normative conflict is 'cross-modal' because the norm compliance and breach cross over different kinds of norms, norms that govern distinct modes of inquiry. By this I mean the following: $\left(\mathrm{NJ}_{\mathrm{F}}\right)$ and $(\mathrm{NJ})$ (and their respective derivative norms $\left(\mathrm{D}-\mathrm{NJ}_{\mathrm{F}}\right)$ and $\left(\mathrm{NJ}_{\mathrm{F}}\right)$ ) regulate what counts as good judgement (and good dispositions to judge). $\left(\phi_{\mathrm{F}}\right)$ and $\left(\mathrm{D}-\phi_{\mathrm{F}}\right)$ do not. They regulate what counts as (put generally) good choices about how to inquire (and good dispositions to choose how to inquire), which is a matter of good intellectual ethics. ${ }^{33}$

Of course, even on the picture under consideration, we will still potentially get old fashioned global-local normative conflicts. For example, one might comply with $\left(\mathrm{NJ}_{\mathrm{F}}\right)$ but not $\left(\mathrm{D}-\mathrm{NJ}_{\mathrm{F}}\right)$. In such a case, one - running out of steam - lazily defers on some question of humanistic interest, but despite doing so comes to know also through first-hand competence. Or, one might satisfy $\left(\mathrm{D}-\mathrm{NJ}_{\mathrm{F}}\right)$ but not $\left(\mathrm{NJ}_{\mathrm{F}}\right)$, as when one manifests a good first-hand knowledge acquiring disposition, but is tricked in the particular case, and so fails to gain first-hand knowledge because she fails to know at all. Likewise, one might comply with (NJ) but not (D-NJ) or (D-NJ) but not (NJ).

Even so, what we do not find in this picture is any influx in collateral normative conflicts, where bad global cognition is somehow 'needed' for the local success. Such cases will remain rare. We don't get one at all by simply supposing someone knows first-hand while disregarding misleading testimony (remember, although Matty violates (D-NJ), (D-NJ) is not applicable to her. $\left(\mathrm{D}-\mathrm{NJ}_{\mathrm{F}}\right)$ is. But she doesn't violate it. Thus, no normative conflict, no collateral normative conflict). Granted, we would get a collateral epistemic conflict on this picture in a situation where it is only because a thinker succumbs (in $F$-conditions) to sheer deference that she is somehow triggered to know in a first-hand-way. This is, while possible,

\footnotetext{
${ }^{33}$ For discussion of intellectual ethics - assessments of which are plausibly beholden to some practical factors - as distinct from the kind of normative assessments in epistemology that are centred around just truth and knowledge (arguably, sealed off from such factors), see Sosa (2007, 89-91), (2015, 43-48) and (2021Ch. 2).
} 
much rarer than knowing first-hand and ignoring misleading testimony.

That said, it should be apparent that cross-modal conflicts are plausibly not rare at all. We already noted one such situation, where in C-conditions a thinker, inquiring in to whether $p$, fails to trigger $F$-conditions (i.e., does not form the intention or mental state $\left.\phi_{F}\right)$, and then comes to know whether $p$ on sheer deference. In such a case, $\left(\phi_{\mathrm{F}}\right)$ and $\left(\mathrm{D}-\phi_{\mathrm{F}}\right)$ are violated while (NJ) and (D-NJ) are complied with. Such cases will be no rarer than cases where a crass pragmatist, inquiring into an ethical or philosophical claim only in case such knowledge is useful on an exam gains such knowledge through sheer deference, e.g., reading from the ethics textbook that 'murder is wrong' and simply taking the author's word for it. ${ }^{34}$ In a case where $C$-conditions don't hold, we get a cross modal conflict when a thinker, for example, refuses to accept testimony - say, that a chemical is poisonous on the basis of a reliable chemist's word - holding out for knowledge-first-hand. Here you violate $\left(\phi_{\mathrm{F}}\right)$ and $\left(\mathrm{D}-\phi_{\mathrm{F}}\right)$, but, since you in fact do $\phi_{\mathrm{F}}$ (even though $C$-conditions don't obtain), your forbearing from acquiring knowledge on sheer deference then complies with $\left(\mathrm{NJ}_{\mathrm{F}}\right)$ and $\left(\mathrm{D}-\mathrm{NJ}_{\mathrm{F}}\right)$.

\section{CONCLUDING REMARKS}

Collateral normative conflicts are rare. At least, they are much rarer than some epistemologists would lead you to think when diagnosing cases where a thinker who knows that $p$ dismisses misleading evidence from reliable sources. But this point becomes apparent only through a better understanding of the appropriateness of aiming, in certain domains of inquiry, not just at knowledge, but at knowledge through first-hand competence (e.g., Sosa 2021, Ch. 1). An implication of this wider picture, however, is that a different kind of normative conflict (see \$6.2) - one that has flown under the radar - is really quite common, and that this is so challenges us to think more carefully about the relationship between norms that regulate (i) what counts as good judgement (and good dispositions to judge); and (ii) what counts as good choices about how to inquire (and good dispositions to choose how to inquire).$^{35}$

\footnotetext{
${ }^{34}$ It is worth noting that the idea that the thinker violates at least some norm here fits snugly with diagnoses of, e.g, moral deference cases as discussed by, among others, Hills (2009) and McGrath (2009). For related discussion, see Enoch (2014) and Matheson, McElreath, and Nobis (2018).

${ }^{35}$ Thanks to Mona Simion, Kevin McCain, and Scott Stapleford for comments on a previous version of this paper and also to an audience at the University of Oxford's Epistemology Seminar (November 2020), hosted by Nick Hughes. This paper was written as part of the Leverhulme-funded 'A Virtue Epistemology of Trust' (\#RPG-2019-
} 


\section{References}

Ballantyne, Nathan. 2014. "Counterfactual Philosophers." Philosophy and Phenomenological Research 88 (2). [International Phenomenological Society, Philosophy and Phenomenological Research, Wiley]: 368-387. https://www.jstor.org/stable/24672901.

Beddor, Bob. 2019. "The Toxin and the Dogmatist." Australasian Journal of Philosophy 97 (4). Routledge: 727-740.

Benton, Matthew A. 2014. "Knowledge Norms." Internet Encyclopedia of Philosophy.

Brown, Jessica Anne. 2018. Fallibilism: Evidence and Knowledge. Oxford University Press.

Carter, J. Adam. 2016. "Sosa on Knowledge, Judgment and Guessing." Synthese, August.

Carter, J. Adam. 2018. "On Behalf of Controversial View Agnosticism.” European Journal of Philosophy 26 (4): 1358-1370. doi:10.1111/ejop.12333.

Carter, J. Adam. 2020. "De Minimis Normativism: A New Theory of Full Aptness." The Philosophical Quarterly.

Douven, Igor. 2003. "The Preface Paradox Revisited." Erkenntnis 59 (3). Springer: $389-420$.

Emerson, Ralph Waldo. 1841. "Self-Reliance." In Ralph Waldo Emerson, Essays, edited by Ralph Waldo Emerson.

Enoch, David. 2014. "A Defense of Moral Deference." The Journal of Philosophy 111 (5). JSTOR: 229-258.

Feldman, Richard. 2006. "Reasonable Religious Disagreements." In Philosophers Without Gods: Meditations on Atheism and the Secular Life, edited by Louise Antony, 194-214. Oxford University Press.

Gibbons, John. 2013. The Norm of Belief. Oxford University Press.

Goldberg, Sanford. 2013. "Defending Philosophy in the Face of Systematic Disagreement." In Disagreement and Skepticism, edited by

302) project, which is hosted by the University of Glasgow's COGITO Epistemology Research Centre, and I'm grateful to the Leverhulme Trust for supporting this research. 
Diego E. Machuca, 277-294. Routledge.

Hills, Alison. 2009. "Moral Testimony and Moral Epistemology." Ethics 120 (1). The University of Chicago Press: 94-127.

Hughes, Nick. 2019. "Dilemmic Epistemology." Synthese 196 (10). Springer: 4059-4090.

Kant, Immanuel. 1996. "An Answer to the Question: What Is Enlightenment?" In What Is Enlightenment?: Eighteenth-Century Answers and Twentieth-Century Questions, edited by James Schmidt. University of California Press.

Kripke, Saul A. 2011. Philosophical Troubles: Collected Papers, Volume 1. Vol. 1. OUP USA.

Lasonen-Aarnio, Maria. 2010. "Unreasonable Knowledge." Philosophical Perspectives 24. JSTOR: 1-21.

Lasonen-Aarnio, Maria. 2014. "The Dogmatism Puzzle.” Australasian Journal of Philosophy 92 (3). Routledge: 417-432.

Leonard, Nick. 2020. "Epistemic Dilemmas and Rational Indeterminacy." Philosophical Studies 177 (3): 573-596. doi:10.1007/s11098018-1195-3.

Littlejohn, Clayton. Forthcoming. "Dividing Away Doxastic Dilemmas." In Epistemic Dilemmas, edited by Nick Hughes. Oxford: Oxford University Press.

Littlejohn, Clayton. 2013. "XV—The Russellian Retreat." Proceedings of the Aristotelian Society (Hardback) 113 (3pt3): 293-320. doi:https: //doi.org/10.1111/j.1467-9264.2013.00356.x.

Makinson, David C. 1965. "The Paradox of the Preface." Analysis 25 (6). JSTOR: 205-207.

Matheson, Jonathan, Scott McElreath, and Nathan Nobis. 2018. "Moral Experts, Deference \& Disagreement." In Moral Expertise: New Essays from Theoretical and Clinical Bioethics, edited by Jamie Carlin Watson and Laura K. Guidry-Grimes, 87-105. Philosophy and Medicine. Cham: Springer International Publishing. doi:10.1007/978-3-319-92759-6_5. 
McGrath, Sarah. 2009. "The Puzzle of Pure Moral Deference." Philosophical Perspectives 23. JSTOR: 321-344.

Pollock, John L. 1986. "The Paradox of the Preface." Philosophy of Science 53 (2). The University of Chicago Press: 246-258. doi:10.1086/289309.

Pritchard, Duncan. 2016. "Seeing It for Oneself: Perceptual Knowledge, Understanding, and Intellectual Autonomy.” Episteme 13 (1). Cambridge University Press: 29-42.

Ross, Jacob. 2010. "Sleeping Beauty, Countable Additivity, and Rational Dilemmas.” Philosophical Review 119 (4). Duke University Press: 411-447.

Ryan, Sharon. 1991. "The Preface Paradox.” Philosophical Studies 64 (3). Springer: 293-307.

Simion, Mona. Forthcoming. "Scepticism about Epistemic Dilemmas.” In Epistemic Dilemmas: New Arguments, New Angles, edited by Kevin McCain, Scott Stapleford, and Matthias Steup. Routledge.

Sosa, Ernest. 2007. A Virtue Epistemology: Apt Belief and Reflective Knowledge, Volume I. Oxford University Press.

Sosa, Ernest. 2010. "How Competence Matters in Epistemology." Philosophical Perspectives 24 (1): 465-475.

Sosa, Ernest. 2015. Judgment Ẽ Agency. Oxford University Press UK.

Sosa, Ernest. 2020. "Default Assumptions and Pure Thought." Manuscript.

Sosa, Ernest. 2021. Epistemic Explanations: A Theory of Telic Normativity, and What It Explains. Oxford University Press.

Srinivasan, A., and J. Hawthorne. 2013. "Disagreement Without Transparency: Some Bleak Thoughts." In The Epistemology of Disagreement., edited by David Christensen and Jennifer Lackey, 9-30. Oxford University Press.

Swindlehurst, Zachary Mitchell. 2020. "The Knowledge Norm of Belief." Thought: A Journal of Philosophy 9 (1): 43-50. doi:https: //doi.org/10.1002/tht3.441. 
Wang, Yuan. 2002. Goldbach Conjecture. Vol. 4. World scientific.

Williamson, Timothy. 2002. Knowledge and Its Limits. Oxford University Press on Demand.

Williamson, Timothy. 2016. "Justifications, Excuses, and Sceptical Scenarios." The New EvilDemon. Oxford University Press, Oxford. Citeseer.

Williamson, Timothy. 2017. “Acting on Knowledge." In Knowledge First: Approaches in Epistemology and Mind, edited by J. Adam Carter, Emma C. Gordon, and Benjamin W. Jarvis, 163-181. Oxford: Oxford University Press.

Williamson, Timothy. 2021. "Epistemological Ambivalence." In Epistemic Dilemmas, edited by Nick Hughes. Oxford: Oxford University Press.

Worsnip, Alex. 2016. "Belief, Credence, and the Preface Paradox." Australasian Journal of Philosophy 94 (3). Taylor \& Francis: 549562. 